Ortodontide ürün

tasarımına sistematik

yaklaşım: Çoklu-durum

analizi ile tasarım

odaklı düşünme

yönteminin kullanımı

\section{A systematic approach to product design in orthodontics: Using multi-case analysis and design thinking}

Arş. Gör. Dr. Muhsin Çifter

İstanbul Üniversitesi, D̉iş Hekimliği Fakültesi, Ortodonti AD., İstanbul

Orcid ID: 0000-0002-6914-0496

Geliş tarihi: 24 Eylül 2019

Kabul tarihi: 26 Kasım 2019

doi: 10.5505/yeditepe.2020.88709

Yazışma adresi:

\section{Dr. Muhsin Cifter}

İstanbul Üniversitesi Diş Hekimliği Fakültesi

Ortodonti A.D. Fatih 34093 İstanbul

Tel: +905323024155

E-mail:mcifter@istanbul.edu.tr

\section{ÖZET}

Amaç: Bu çalışma, tasarım odaklı düşünme yönteminin yeni ürün geliştirme süreçlerinde nasıl etkin kullanılabileceğine dair, ortodontistler ve tasarımcılar arası bir iş birliği modelini ortaya koymayı hedeflemektedir.

Gereç ve Yöntem: Bu çalışmada, tasarım odaklı düşünme modelinden faydalanılarak, ortodonti alanına yönelik 2 ürün geliştirme çalışması bütünsel olarak çoklu-durum analizi yöntemi ile değerlendirilmiştir. Değerlendirme sonuçlarının karşılaştıııması çapraz durum sentezi ile yorumlanarak bir iş birliği tasarım modeli önerisi oluşturulmuştur.

Bulgular: Seçilen her iki çalışma da, tasarım odaklı düşünme yöntemi kullanılarak ortodonti alanına yönelik ürün tasarımı sürecini ortaya koymakla birlikte, bağlam farklılıklarından dolayı farklı yaklaşımların benimsenmesini gerektirmiştir. Durumlar çapraz-durum sentezi ile değerlendirildiğinde, tasarım iş birliği açısından önemli benzerliklerinden 9 tema oluşturmuştur. Bu temalar, tasarım odaklı düşünme modelinin literatürde belirtilen ilham alma, fikirleştirme ve hayata geçirme aşamalarıyla ilişkilendirilerek tasarım sürecinde uzman hekim ve tasarımcıların iş birliği etkinliğini artıracak "anlamlandırma", "somutlaştırma" ve "doğrulama" aşamalarının tespitini sağlamıştır. Bu doğrultuda ortodonti alanına uygun bir tasarım iş birliği modeli geliştirilmiştir.

Sonuç: Ortodonti alanında kullanılan ekipmanların gerek hasta gerekse de hekim deneyimine olan etkisi ve bu ekipmanların tasarım süreçlerinin meslek pratiği ile doğrusal ilişkisi ürün geliştirme sürecinde tasarımcı - uzman hekim iş birliğini kaçınılmaz kılmaktadır. Bu doğrultuda tasarım odaklı düşünme modelinin etkin kullanımı, tasarlanacak yeni ürünlerin hasta odaklı ve efektif olmasını sağlayacaktır.

Anahtar kelimeler: Ortodonti, tasarım odaklı düşünme, endüstriyel tasarım

SUMMARY

Aim: The aim of this study was to present a collaborative model between orthodontists and designers on how to use the design thinking method effectively in new product development processes.

Materials and Method: In this study, two product development studies using design thinking model in the field of orthodontics were evaluated holistically by multi-case analysis method. The comparison of the evaluation results was interpreted with cross-case synthesis and a design model proposal for collaboration was formed.

Results: Although both cases reflected designing products for orthodontics by using the design thinking method, different approaches were required because of the contextual differences. When the cases were evaluated with cross-case synthesis, 9 themes were constituted from their important similarities in terms of design collab- 
oration. These themes had then been associated with the inspiration, ideation and implementation phases of the design thinking model, which enabled the identification of the "sense-making", "embodying" and "verification" stages that will increase the collaboration efficiency of the specialists and designers in the design processes. In this direction, a design collaboration model suitable for orthodontics has been developed.

Conclusion: The effect of the equipment used on both the patient and the specialists in the field of orthodontics and the linear relationship between the design processes and the professional practice of these equipments, make the cooperation between designers and specialists inevitable in product development process. In this direction, effective use of design thinking model will ensure that the new products to be designed will be patient-centered and effective.

Keywords: Orthodontics, design thinking, industrial design

\section{Giriş}

Diş hekimliği hasta odaklı bir süreç olup, bu süreçte pek çok ekipmanın kullanımı gerekmektedir. Bu nedenle hasta deneyimi, tedavi sürecinin kalitesi açısından önemli bir unsur olarak öne çıkmaktadır. Mills ve ark. ${ }^{1}$ sistematik literatür taraması ile gerçekleştirdikleri çalışmalarında, hasta odaklı yaklaşıma diş hekimliği alanında oldukça az yer verildiğini belirtmişlerdir. Çalışmada, diş hekimliği alanına özgü hasta odaklı yaklaşımların geliştirilebilmesi için kanıta dayalı araştırmaların yürütülmesinin önemi vurgulanmıştır. Bu genel çerçeveden özele inildiğinde, hasta-hekim arasındaki tüm tedavi işlemleri dâhilinde kullanılan ürünler de, hasta-odaklı yaklaşımlar açısından önemli sistemsel bir bileşen olarak ortaya çıkmaktadır.

Günümüzde klinik diş hekimliği, dijital teknoloji ve malzeme alanındaki gelişmeler doğrultusunda önemli dönüşümler geçirmekte olup, bu anlamda "tasarım" da inovasyon açısından bir strateji öğesi olarak öne çıkmaktadır. ${ }^{2}$ Bu noktada, doğru teknoloji transferi ve inovasyon açısından araştırmacıları, üniversiteleri, üreticileri ve hekimleri bir araya getirecek bağlantıların önemi ortaya çıkmaktadır. ${ }^{3}$ Özellikle yeni tedavi yöntemleri ve yeni ürünlerin kullanımı ile ilgili olarak, günümüz sağlık sektörünü önemli şekilde etkileyen kanıta dayalı uygulamalar diş hekimliğini de etkileyerek "kanıta dayalı diş hekimliği" alanının ortaya çıkmasını sağlamıştır. Amerika Diş Hekimleri Birliği kanıta dayalı diş hekimliğini "en güncel bilimsel bilgilere dayanarak kişiselleştirilmiş ağız sağlığı bakımı sağlayan tedavi kararları için hasta-merkezli bir yaklaşım" şeklinde önermektedir. ${ }^{4}$ Bu nedenle kanıta dayalı diş hekimliği, yeni ürün geliştirme süreçleri için de önem arz etmektedir. Güler ve ark., kanıta dayalı diş hekimliği vasıtasıyla ürün ve teknolojilerin geliştirilme süreçlerinin klinik kararlara dayandırabileceğini ifade et- mektedir. ${ }^{5}$ Bununla birlikte, kanıta dayalı araştırmalar her ne kadar deneysel ve niceliksel yaklaşımlarla ilişkilendirilse de, kalitatif yaklaşımların sağlık alanındaki deneyim temelli problemlere ilişkin derin bilgi sunmaları açısından kanıta dayalı uygulamalardaki önemi vurgulanmaktadır. ${ }^{6-8}$ Çünkü objektif ve bilimsel olarak nitelendirilebilecek kanıtlar uygulamaya geçtiğinde subjektif ve sosyal süreçlere dönüşmektedir. ${ }^{9}$ Kalitatif araştırmalar ise deneyimlere ilişkin hikayesel biçimde ifade edilen anlamların tespitine, ve bu doğrultuda empati sağlayarak sağlık alanında yeni fikirlerin ve yaklaşımların ortaya çıkmasına olanak sağlamaktadır. ${ }^{7}$ Bu doğrultuda tasarım sürecinde yenilikçi fikir ve doğru karar verme konusunda kalitatif ve insan merkezli bir yaklaşım olarak ortaya çıkan tasarım odaklı düşünmenin diş hekimliği alanında yeni ürün geliştirme sürecine katkı sağlayabileceğinden bahsedilebilir. ${ }^{10}$

Tasarım odaklı düşünme, günümüz tasarım dünyasını önemli biçimde etkilemenin dışında, sağlık sektörü de dâhil olmak üzere birçok farklı alanda uygulamalarına rastladığımız bir süreç modelidir. Süreç, özünde sistematik bir inovasyon modeli olup son kullanıcıların intiyaç ve beklentilerini tam olarak anlamayı ve bu doğrultuda çözümler ortaya koyabilmeyi amaçlamakta ve empatiyi merkezine almaktadır. ${ }^{10}$ Çünkü tasarım süreci, lineer bir problem çözme sürecinden öte, karmaşık ve tam olarak formüle edilemeyen, belirsiz koşulları barındıran ve kesin doğru olarak kabul edilebilecek tek bir çözümü işaret etmeyen bir süreçtir. ${ }^{11}$ Bunun bir nedeni de, çözümü tasarımcıların konuyu algılama şeklinden bağımsız olarak düşünmemizdir. Bu da tasarımı bir disiplin olarak prensiplere, kurallara ve tanımlı strüktürlere dayalı işleyen bilim alanlarından ayırmaktadır. ${ }^{11}$ Tasarım odaklı düşünme ise lineer bir yapıdan ziyade iç içe geçmiş ve kendi içerisinde bir döngüye sahip olan üç aşamadan oluşmaktadır: ilham alma, fikirleştirme ve hayata geçirme. ${ }^{12}$ Hendricks ve ark. bu üç aşamanın, derinlemesine araştırmalarla paydaşların arzularının ve yaşadıkları zorlukların anlaşıması (ilham alma), fikirlerin geliştirilmesinde iş birliği sağlama (fikirleştirme) ve çözümlerin paydaşlardan gelen geribildirimler doğrultusunda optimize edilmesi (hayata geçirme) açısından sağlık sektörüne katkı sağladığını savunmuşlardır. ${ }^{13}$

Yapılan literatür taramasında, tasarım odaklı düşünmeyi merkeze alan ortodonti alanında herhangi bir çalışmaya rastlanmamıştır. Bu çalışma, tasarım odaklı düşünme yönteminin, ortodontiye özgü yenilikçi ürün tasarlama süreçlerinde nasıl etkin kullanılabileceğine dair, ortodonti uzmanları ve tasarımcılar arası bir iş birliği modelini ortaya koymayı hedeflemektedir.

\section{GEREÇ VE YÖNTEM}

Bu çalışmada, tasarım odaklı düşünme modelinden faydalanılarak, 2015-2019 yılları arasında İstanbul Üniver- 
sitesi Diş Hekimliği Fakültesi Ortodonti Anabilim Dalı ve Mimar Sinan Güzel Sanatlar Üniversitesi Mimarlık Fakültesi Endüstri Ürünleri Tasarımı Bölümü iş birliği ile gerçekleştirilmiş olan ortodonti alanına yönelik 2 ürün tasarımı çalışması, bütünsel olarak çoklu-durum analizi yöntemi ile değerlendirilmiştir. Bu değerlendirmenin gerçekleştirilmesinde teorik önerme olarak, "tasarım odaklı düşünme" yönteminin Brown tarafından önerilen "ilham alma, fikirleştirme ve hayata geçirme" aşamaları kullanılmıştır. ${ }^{12}$

Bu doğrultuda Yıldırım ve Şimşek'in önerdiği "bütüncül çoklu durum deseni" benimsenmiş, birden fazla kendi başına ve bütüncül olarak algılanabilecek durum önce kendi içerisinde bütüncül olarak incelenmiş, daha sonra ise birbirleriyle karşılaştırılmıştır. ${ }^{14}$

Yin R.'ye göre, durum çalışmalarının beş bileşeni bulunmaktadır. Bu bileşenler: (1) sorular, (2) önermeler, (3) durumlar, (4) veri ile önermeleri birbirine bağlayan teknik ve (4) bulguları değerlendirme kriterleri, olarak karşımıza çıkmaktadır. ${ }^{15}$ Bu çalışmada, "dental ürün tasarlama sürecinde hasta odaklı çözümleri sağlayabilmek için, tasarım yoluyla düşünme ile"nasıl" bir disiplinler arası çalışma süreci geliştirilebilir?" sorusu sorulmuştur. Tablo 1,

Tablo 1. Çoklu durum analizi bileşenleri

\begin{tabular}{|c|c|}
\hline $\begin{array}{l}\text { Durum } \\
\text { Bileşenleri }\end{array}$ & Gerçekleştirilen Araştırma Özelindeki Açıklamalar \\
\hline Sorusu & 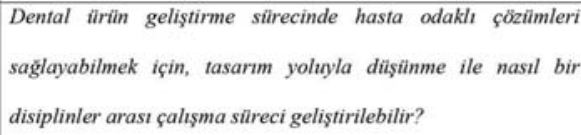 \\
\hline Önerme & $\begin{array}{l}\text { Tasarım odakh düşünme yöntemi ile gerçekleştirilecek ürün } \\
\text { geliş̧tirme çalışmaları, dental ürün geliştirme sürecinde bir iş } \\
\text { birliği modeli oluşturulmasında katkı sağlayabilir. }\end{array}$ \\
\hline Durumlan & $\begin{array}{l}\text { 1. Dental fotoğraflamaya yönelik ürrïn tasarım projesi } \\
\text { 2. Dudak-damak yarı̆̆ı olan bebeklere yönelik ölçü kaşı̆̆t } \\
\text { tasarımı projesi }\end{array}$ \\
\hline $\begin{array}{lr}\text { Veri İle } & \text { Ōnermelerini } \\
\text { Birbirine } & \text { Bağlama } \\
\text { Tekniği } & \end{array}$ & 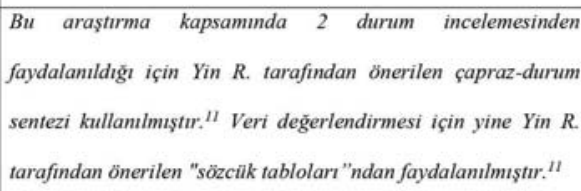 \\
\hline Bulguları Değerlendirme & $\begin{array}{l}\text { Tasarım odaklt düşünme yönteminin } 3 \text { bileşeni olan ilham alma, } \\
\text { fikirleştirme ve hayata geçirme aşamalarmm iş birliği } \\
\text { sürecindeki etkisi teorik bir önerme olarak kabul edilip, } \\
\text { bulgulart değerlendirme kriterleri olarak belirlenmiştir." }\end{array}$ \\
\hline
\end{tabular}

gerçekleştirilmiş olan "çoklu-durum analizi" özelindeki bileşenleri göstermektedir.

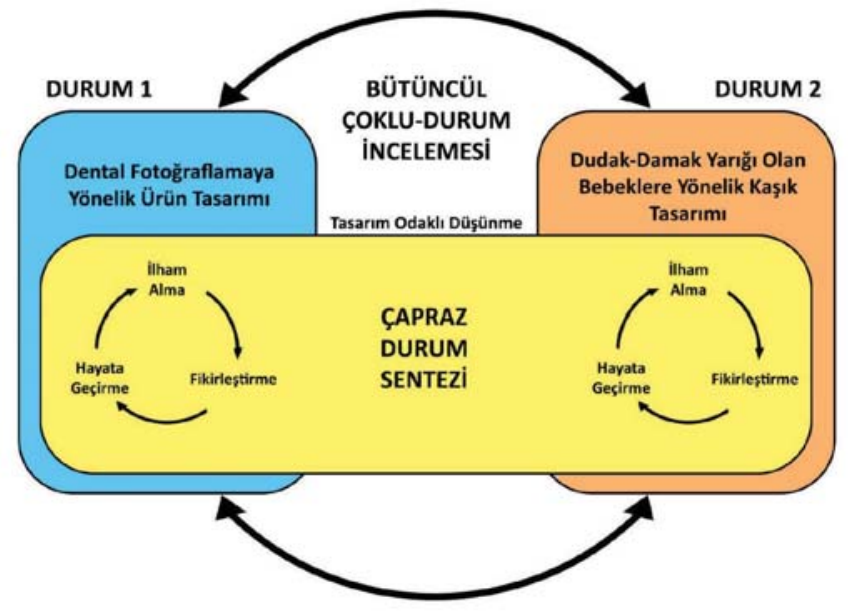

Şekil 1. Metodolojik yaklaşım

Şekil 1'de görüldüğü üzere gerçekleştirilen tasarım çalışmaları bu makale kapsamında bütünsel olarak değerlendirilmiş olsa da, kendi içerisinde ayrı metodolojik yaklaşımları olmuştur. Bu yaklaşımlar ve araştırmanın amacı doğrultusundaki bulgular öncelikle ayrı alt bölümler altında değerlendirilmiş, daha sonra bir arada ve çapraz durum sentezi dâhilinde ele alınmıştır.

Çoklu Durum Analizine Dâhil Edilen Tasarım Çalışmaları:

1. Dental Fotoğraflamaya Yönelik Ürün Tasarımı Projesi (Proje 1)

Dental fotoğraflama, diş hekimlerinin gerçekleştirilen tedaviye yönelik önemli aşamaları kayıt altına almalarına olanak sağlamanın yanında ortodonti disiplinine hastalarla iletişim, uzmanın kendini değerlendirebilmesi, tedavi planlaması, bilimsel araştırmalar için veri sağlama, eğitim ve hatta pazarlamaya kadar birçok alanda katkı sağlamaktadır. ${ }^{16-20} \mathrm{Bu}$ alanda özellikle kullanılan dijital teknolojilere odaklanan bilimsel çalışmalar olmasına karşın, bu teknolojilerin klinik ortama uyumu ve hasta ve hekim deneyimleri açısından değerlendirilmesine ilişkin bir çalışmaya literatürde rastlanmamıştır.

Bu araştırma, 16-20 yaşları arasında 20 hastanın ve 12 uzmanın, ortodonti tedavisinin başında uygulanan dental fotoğraflama süreci konusundaki görüşlerine odaklanan, daha önce Cifter (2018) ve Altıparmakoğulları ve diğ (2017) tarafından yayımlanmış olan iki ayrı kalitatif gözlem ve mülakat çalışması verileri değerlendirilerek başlamıştır. $^{21,22}$

Kalitatif değerlendirmelerin güvenirliği Patton (2015) tarafından önerilen "Güvenilirliği ve Faydaları Artırmak için On Sistematik Analiz Stratejisi (Ten Systematic Analysis Strategies to Enhance Credibility and Utility)" yöntemlerinden "birden fazla kalitatif veri kaynağının içerilmesi ve çeşitlenmesi: görüşme, gözlem ve doküman analizi" ve "araştırmacıların çeşitlenmesi"nin kullanılmasıyla sağlanmıştır. ${ }^{23}$ Bu doğrultuda her iki örnek durum çalışmasında da hem veri toplama hem de verilerin değerlendirilme sürecinde "çeşitleme" uygulanmıştır. Özellikle veri değerlendirme sürecinde her iki disiplinden de araştırmacıların 
olması, bu araştırmanın öne çıkan özelliğidir.

Toplanan veriler kalitatif ve içerik analizinin bir yaklaşımı olan "tematik analiz" yöntemiyle değerlendirilmiştir. Bu yöntem, kalitatif araştırma sonucu toplanan veri parçacıklarının tanımlanması amacıyla "kodlanması" ve tespit edilen kodların gruplanması sayesinde sorgulama amacına ilişkin üst "temaların" oluşturulmasını kapsamaktadır. ${ }^{14,24} \mathrm{Bu}$ doğrultuda toplanan tüm sözel verilerin tam metin yazılı dökümü yapılmış ve QSR NVivo 11 (QSR Int. Pty. Ltd., UK) kalitatif analiz yazılımı kullanılarak veriler analiz edilmiştir. Daha sonra elde edilen bulgular dâhilinde bir tasarım çalışması yürütülmüştür. Araştırmada izlenilen yaklaşım Şekil 2'de özetlenmiştir.

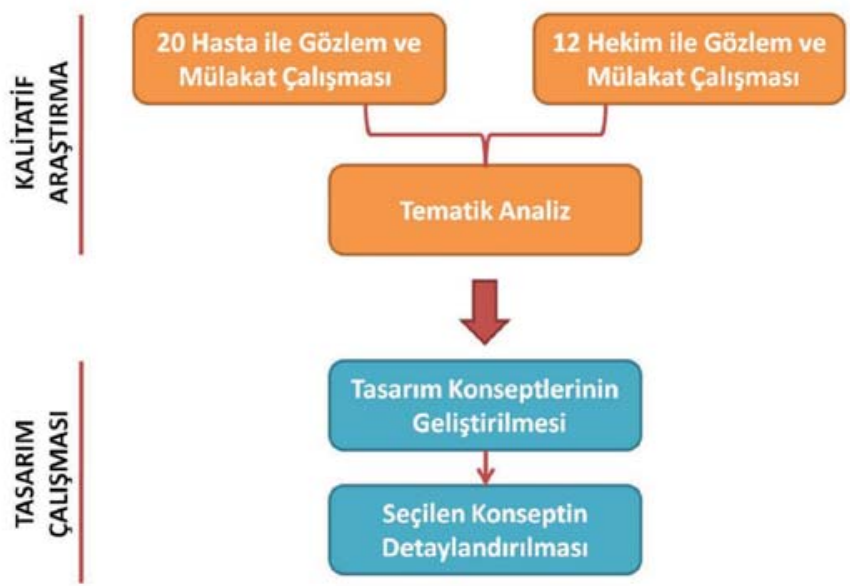

Şekil 2. Proje 1'de uygulanan metodolojik yaklaşım

Araştırmanın "ilham alma" aşamasında gerçekleştirilen çalışmalar, hâlihazırda kullanılan DSLR fotoğraf makinelerinin klinik ortama uygun olmadığını ve hasta ve hekim açısından deneyimlerini olumsuz yönde etkileyecek durumlara neden olduğunu göstermiştir. ${ }^{21,22} \mathrm{Bu}$ aşamada her iki disiplinden araştırmacıların ortak bir anlayış ve yaklaşım geliştirebilmesi için verilerin değerlendirilme sürecinde düzenli toplantılar yapılmıştır. Bu toplantılarda araştırma verileri üzerinden; DSLR fotoğraf makinelerinin ağır ve tek elle kullanıma uygun olmaması, kullanımının belirli bir eğitim gerektirmesi, pil ömrüne dair sorunlar ve ideal olarak süreçte farklı flaş seçeneklerine yönelik ihtiyaç gibi geliştirme alanları tespit edilmiştir. Bununla birlikte, DSLR fotoğraf makinelerinin dezenfeksiyonu ve klinik ortam içerisinde konumlandırılmasıyla ilgili problemlere ve bunlara yönelik olası çözümlerin geliştirilecek olan tasarıma nasıl yön verebileceği tartışılmıştır.

Fikirleştirme aşamasında, hasta ve uzmanlardan elde edilen bulgular bir arada değerlendirilerek ortak sonuçları doğrultusunda dental fotoğraflamaya yönelik bir ürün tasarımı çalışması gerçekleştirilmiştir. Bu aşamada elde edilen araştırma verileri sonucu 5 farklı tasarım önerisi geliştirilmiş, bu öneriler Pugh matriks analiziyle değerlendirilmiştir. Bu yöntem seçilen konseptlerin, tasarımda olması istenilen kriterler doğrultusunda bir tablo üzerinden değerlendirilmesini sağlamaktadır. Bunun için konseptler üste, kriterler ise tablonun yan kısmına koyulmakta, eğer bir tasarım kriter doğrultusunda avantaj sağlıyorsa 1, sağlamıyorsa 0, dezavantaj sağlıyorsa -1 verilmekte, daha sonra bu değerler toplanarak en başarılı konsept bulunmaktadır ${ }^{25,26}$. Bu amaçla, kararlaştırılan 8 tasarım kriteri doğrultusunda (kullanım kolaylığı, kurulum kolaylığı, üretim kolaylığı, düşük maliyet, kişi sayısının azaltılması, ortama uygunluğu, dezenfeksiyon kolaylığı ve veri koruması) tasarımlar puanlandırılmış ve kriterleri en iyi karşılayan tek bir öneri seçilmiştir. Süreç içerisinde geliştirilen önerilerin araştırmanın amacı doğrultusunda uygunluğunun sağlanabilmesi için bu öneriler bir önceki aşamada elde edilen bilgi ile düzenli olarak değerlendirilmiştir. Pugh martiks analizi sonucu seçilen konsept, akıllı telefona entegre edilebilir bir sistem tasarımını işaret etmiştir (Şekil 3).

\begin{tabular}{|c|c|c|c|c|c|}
\hline KRITERLER & $\begin{array}{l}\text { K.11 Tavana Monte } \\
\text { sistem }\end{array}$ & $\begin{array}{l}\text { K.2. Dental } \\
\text { fotogrraflame seti }\end{array}$ & \begin{tabular}{|l|} 
K.3: Akill telefons \\
entegre sistem
\end{tabular} & 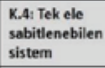 &  \\
\hline Kullanim kolaytü & 1 & 1 & 1 & -1 & -1 \\
\hline Kurrulum koleytits & -1 & 1 & 1 & 1 & -1 \\
\hline Oretim kolaylib! & -1 & -1 & 1 & 1 & 1 \\
\hline Dü̧̧̈̈kmaliyet & .1 & -1 & 1 & 1 & 1 \\
\hline $\begin{array}{l}\text { Kesis saysinu } \\
\text { azaltmasi }\end{array}$ & 1 & 1 & 1 & 1 & 1 \\
\hline Ortama uygunlugéu & .1 & 1 & 1 & 0 & -1 \\
\hline $\begin{array}{l}\text { Sterilizasyon } \\
\text { koleylıb }\end{array}$ & 0 & 1 & 1 & -1 & 0 \\
\hline Verikorumesy & 0 & 0 & 1 & 0 & 0 \\
\hline TOPLAM PUAN & -2 & 3 & 8 & 2 & 0 \\
\hline
\end{tabular}

Şekil 3. Tasarımcıların geliştirdiği tasarım konseptlerinin Pugh Matriks analiziyle değerlendirilmesi

Tasarım sürecinin "hayata geçirme" aşamasında; seçilen konsept detaylandırımış ve bilgisayar destekli tasarım vasıtasıyla Rhinoceros (5.0 SR8, McNeel) yazılımı kullanılarak üç boyutlu kabuk tasarımı yapılmıştır. Bu model daha sonra eklemeli üretim yöntemleri vasıtasıyla üç boyutlu basılarak prototipi elde edilmiştir. Eklemeli üretim, günümüzde giderek yaygınlaşan bir hızlı üretim ve prototipleme teknolojisi olup bir ürünün katmanlar halinde ilgili malzemenin uygulanarak oluşturulmasıdır. ${ }^{27}$ Eklemeli üretimle ortaya çıkan prototip tekrar ilk aşamadaki bulgular ile değerlendirilerek daha da geliştirilmesine yönelik öneriler ortaya konulmuştur. Bu aşamada sürecin doğru ilerlemesi ve hedeflenen tasarım kriterlerinin karşılanabilmesi için tasarımcılar ve diş hekimleri arasında düzenli geribildirim toplantıları yapılmıştır.

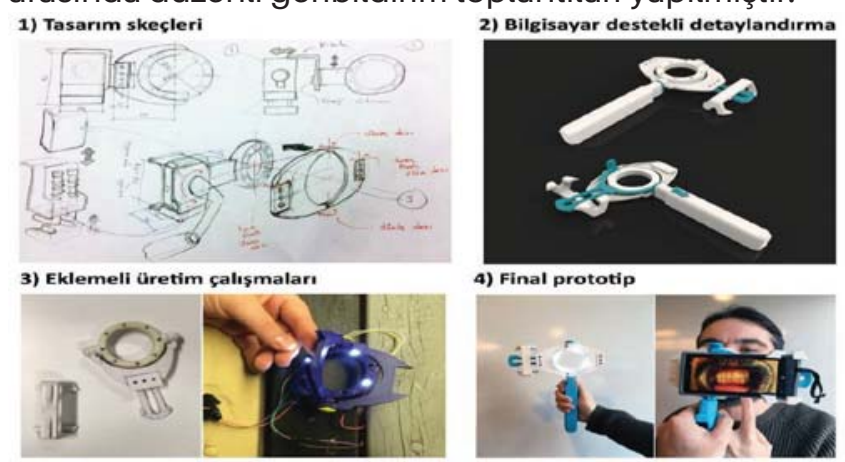

Şekil 4. Proje 1 ürün tasarlama sürecine ait örnek görüntüler 
Şekil4 ürün tasarlama sürecine ilişkin yapılan çalışmalardan örnekler sunmaktadır.

\section{Dudak Damak Yarıklığı Olan Bebeklere Yönelik Kaşık Tasarımı Projesi(Proje 2)}

Dudak damak yarığına sahip bebeklerin planlama ve tedavi süreçlerinde ölçü alınarak model elde edilmesi sıklıkla tekrarlanan bir işlem olup dijital tarayıcılar ile bu işlemin bebeklerde gerçekleştirilmesi henüz güvenilir sonuçlar vermemektedir. ${ }^{28-30}$ Jacobson ve Rosenstein, bu doğrultuda ölçü kaşıklarının öneminden bahsetmiş, bu amaçla üretilen farklı ebatlarda akrilik ve metal kaşıklar olmasına rağmen, bu ürünlerde modifikasyonlara intiyaç duyulabildiğini veya gerekli durumlarda olguya özel ürünlerin de hekimler tarafından yapıldığını belirtmiştir. ${ }^{28}$ $\mathrm{Bu}$ nedenle olgular arasında önemli derecede çeşitlilik gösteren dudak damak deformitelerine yönelik ölçü alma işlemi, hekimler açısından zorlayıcı bir işlem olup, farklı olgulara uyum sağlayabilecek uyarlanabilir bir ölçü kaşığı olmamasından dolayı hekimleri kendi çözümlerini üretmeye zorlamakta, bebekler için de ölçü alma işlemini uzatmaktadır.

Buradan yola çıkılarak farklı tipte dudak damak yarığına sahip olgular için uyarlanabilir tipte bir ölçü kaşığı tasarımı için İstanbul Üniversitesi Diş Hekimliği Fakültesi Ortodonti Anabilim Dalı ve Mimar Sinan Güzel Sanatlar Üniversitesi Endüstri Ürünleri Tasarımı bölümü iş birliği ile bir çalışma başlatılmıştır. Şekil 5, çalışma sürecini özetlemektedir.

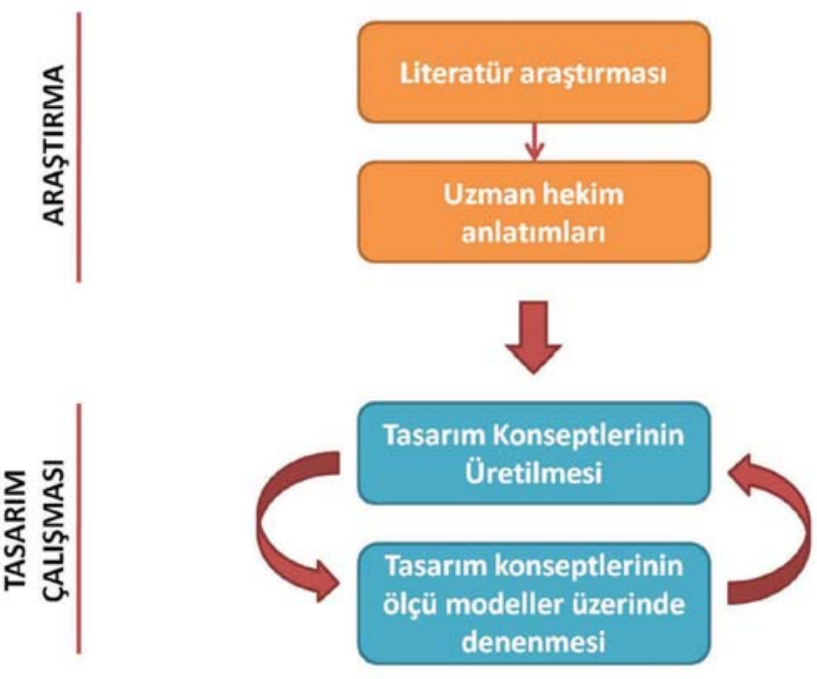

Şekil 5. Proje 2'de uygulanan metodolojik yaklaşım

Araştırmanın "ilham alma" aşamasında, tasarım sürecinde intiyaç duyulacak verinin toplanabilmesi için gerekli olan örneklemin hassas ve incinebilir bir topluluğu içermesi nedeniyle alan çalışması yerine alternatif bir yaklaşım aranmıştır. Bu doğrultuda süreç tasarımcılara ortodonti uzmanları tarafından detaylı olarak açıklanmış, ayrıca alanla ilgili akademik çalışmalar da tasarımcılarla paylaşıımıştır. Bu tasarım çalışması, dental fotoğraflama çalışmasından farklı olarak daha detaylı tıbbi bir içeriğe sahip olmasından dolayı ortodonti uzmanlarının ilham alma sürecinde daha yönlendirici ve tanımlayıcı olmasını gerektirmiştir.

"Fikirleştirme" ve "Hayata Geçirme" aşamalarındaki süreç, bir önceki çalışmayla benzer tutulmuş, ancak kullanıcı odaklı (hasta ve hekim) çözümlerin oluşturulabilmesi ve bu çözümlerin uygulanabilirliğinin test edilmesi için farklı bir yaklaşımdan faydalanılmıştır. Bu doğrultuda tek ve çift taraflı dudak damak yarığı bulunan bireylerin maksiller ark form ve boyutlarının incelendiği bir çalışmadan faydalanılıp, bilgisayar destekli tasarım yazıımı Rhinoceros 5 (McNeel Europe $^{\mathrm{Tm}}$ ) kullanılarak farklı tiplerde damak yarığını temsil eden modeller oluşturulmuş ve bu modellerin üç boyutlu çıktıları alınmıştır. ${ }^{31}$ Bu modeller yardımı ile tasarlanan çözümler, eklemeli üretimle somut prototipler haline getirilmiştir. Meydana getirilen her prototip farklı tipte dudak damak yarığını temsil eden modeller üzerinde denenerek hasta odaklı bir yaklaşımla süreç içerisinde karşılaşılan sorunlar aşamalı olarak çözümlenmeye çalışılmıştır. Dolayısıyla bu iki aşamanın bu çalışma dâhilinde daha lineer bir yapıdan ziyade, iç içe geçtiği söylenebilir. Tasarım sürecinde, malzeme mukavemeti ve esnekliği, farklı özellikteki olgulara yönelik çözüm saptama ihtiyacı, ürünün olası maliyeti ve hasta açısından olası riskleri üzerinde durulmuştur. Şekil 6
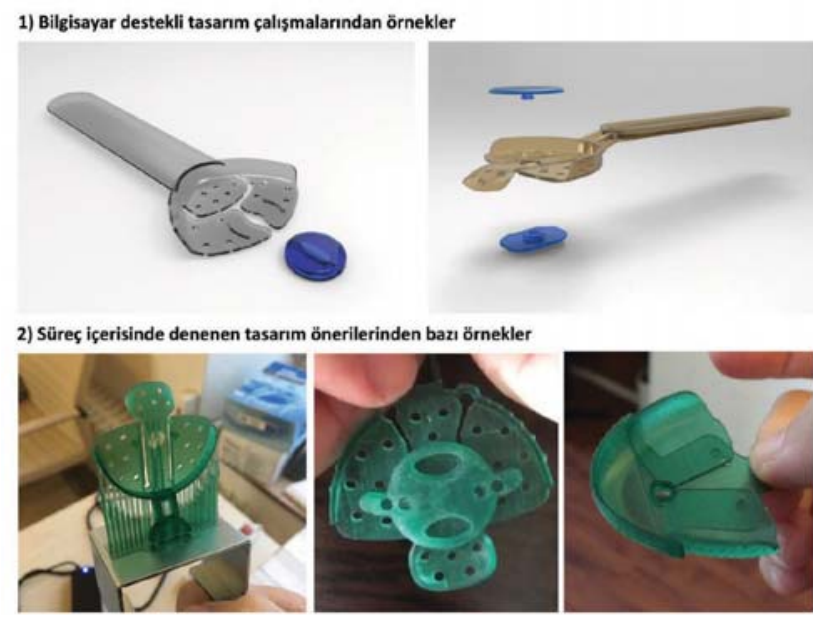

Şekil 6. Proje 2 ürün tasarlama sürecine ait örnek görüntüler gerçekleştirilen prototip ağırlıklı ürün tasarlama sürecinden bazı örnekleri sunmaktadır.

Çalışmanın tasarım aşamasının bitirilmesini takiben yine 3 boyutlu vaka modelleri üzerinden (klinik ortamın dışında) denenmesi yapılmıştır. Kullanılan üç boyutlu yazıcı malzemesi (SLA reçine) ile oluşturulan prototipin, hasta üzerinde denemesinin uygun olmaması ve klinik çalışmalar için gerekli izinlerin alınması gerekliliğinden dolayı bu proje ilk projeden farklı bir metotla gerçekleştirilmiştir. Bu doğrultuda ortaya çıkan ürün son-kullanıcıya halen uygun olmayıp tasarım konseptinin prototip geliştirme sürecini ortaya koymaktadır.

\section{BULGULAR}

Her iki çalışmada da ilham alma, fikirleştirme ve hayata 
geçirme aşamalarını içeren benzer bir süreç planlanmış olmasına karşın, çalışmaların bağlam farklııklarından dolayı farklı iş birliği stratejilerinin benimsendiği görülmektedir (Tablo 2).

Tablo 2. Her iki projeye ait bulgular ve bu bulgulardan elde edilen ana temalar

\begin{tabular}{|c|c|c|c|}
\hline $\begin{array}{l}\text { Tasarım } \\
\text { odakh } \\
\text { düşünme }\end{array}$ & \begin{tabular}{lrr} 
Dental & \multicolumn{2}{c}{ Fotoğraflamaya } \\
Yōnelik & UUrün & Tasarım \\
Projesi & &
\end{tabular} & $\begin{array}{l}\text { Dudak Damak Yarıklı̆ı } \\
\text { Olan Bebeklere Yönelik } \\
\text { Kaşı Tasarımı Projesi }\end{array}$ & Ortak Tema \\
\hline \multirow[t]{2}{*}{ fltham Alma } & 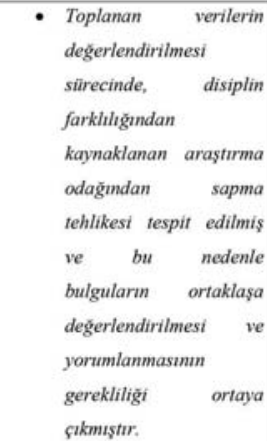 & $\begin{array}{l}\text { - Tasarıma komu olan } \\
\text { örneklem, hassas ve } \\
\text { incinebilir bir } \\
\text { topluluğu } \\
\text { içerdiginden } \\
\text { tasarmmcilar dis } \\
\text { hekimleri tarafindan } \\
\text { yönlendirilmis ve } \\
\text { düzenli geri bildirim } \\
\text { almalart gerekmiştir. }\end{array}$ & $\begin{array}{l}\text { Tasarımeılan } \\
\text { Yönlendirmenin } \\
\text { Gerekliliği }\end{array}$ \\
\hline & 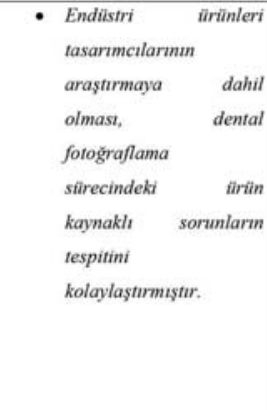 & $\begin{array}{l}\text { - Endïstriyel } \\
\text { tasarımcılar bilimsel } \\
\text { yayınlarzn yam sıra, } \\
\text { malzeme ve üretim } \\
\text { yöntemleri açısından } \\
\text { referans } \\
\text { sağlayabilecek diğer } \\
\text { alanları arassturmıs } \\
\text { ve olası çözïmlerle } \\
\text { ilgili hekimlere farklt } \\
\text { bir perspektif } \\
\text { sunmuşlardir. }\end{array}$ & $\begin{array}{l}\text { Tasarımciların } \\
\text { Farkh Bir } \\
\text { Perspektif Sunması }\end{array}$ \\
\hline
\end{tabular}

\begin{tabular}{|c|c|c|c|}
\hline & 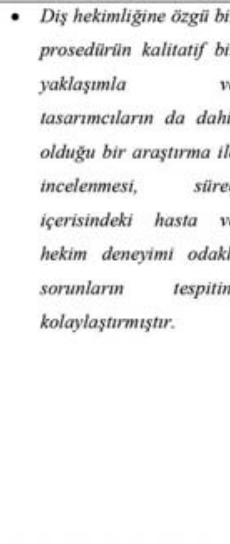 & 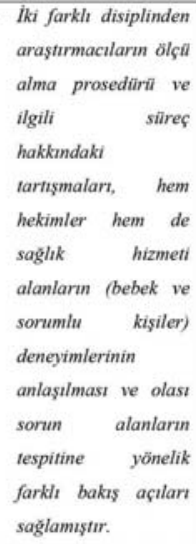 & $\begin{array}{l}\text { Hasta-Odakh } \\
\text { Sorun Tespiti } \\
\text { Için Ortak } \\
\text { Yorumlamanın } \\
\text { Önemi }\end{array}$ \\
\hline \multirow[t]{2}{*}{ Fikirleştirme } & $\begin{array}{l}\text { - Ilk tasarm önerilerini } \\
\text { ortaya çıkmastmd } \\
\text { tasarmmctlarm fikirse } \\
\text { olarak kastlanmasın } \\
\text { önlemek için di } \\
\text { hekimleri gerekli olduğ } \\
\text { takdirde dahil olmustur }\end{array}$ & $\begin{array}{lr}\text { Assamalı } & \text { ïrün } \\
\text { gelisstirmeye } & \text { olanak } \\
\text { sağlayacak } & \text { ilk } \\
\text { tasarım önerisint } \\
\text { tasarımcilar } \\
\text { kendileri gelişstirmiş. } \\
\text { ardından } \\
\text { hekimlerine } \\
\text { sunmuştur. }\end{array}$ & $\begin{array}{l}\text { flk Fikir Geliştirme } \\
\text { Sürecinde } \\
\text { Tasarımeıların } \\
\text { Özgür Bırakılması }\end{array}$ \\
\hline & 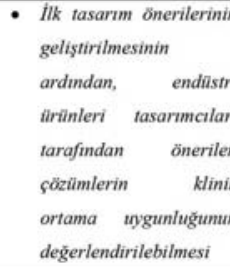 & 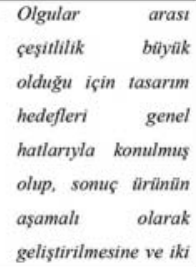 & $\begin{array}{l}\text { Tasarımın Doğru } \\
\text { Ilerlemesi Için } \\
\text { Uzman } \\
\text { Görușünün } \\
\text { Önemi }\end{array}$ \\
\hline
\end{tabular}



Bulgular çapraz olarak değerlendirildiğinde tasarım odaklı düşünme modelinin her aşamasının ortodonti alanında etkin bir iş birliği sağlamasına yönelik ulaşılan temalar Tablo 2'de verilmiştir.

\section{TARTIŞMA}

Bu çalışmada tasarım odaklı düşünme modelini oluşturan ilham alma, fikirleştirme ve hayata geçirme aşamaları iki farklı proje sürecine dâhil edilmiş ve süreçler karşılaştırılarak örnek bir iş birliği modeli oluşturulmaya çalışılmıştır. Günümüz sağlık sisteminde, insan odaklı ürün tasarımlarının yapılarak, hasta - hekim memnuniyetinin üst seviyeye çıkartılabilmesi için, öncelikli olarak ihtiyaçların belirlenmesi ve bu intiyaçlar doğrultusunda da tasarımcı ve uzman hekimlerin dâhil olduğu çok disiplinli çalışmaların gerçekleştirilmesi önem taşımaktadır. 
Çalışmaya dâhil edilen projelerde, tasarım süreci içerisindeki her aşamada iş birliği ve ortak karar süreçleri gerekmiş olmakla birlikte; "ilham alma" aşamasında uzman hekimlerin daha aktif olduğu, "fikirleştirme" aşamasında endüstri ürünleri tasarımcılarının daha aktif olduğu, "hayata geçirme" aşamasında ise daha dengeli bir iş birliği sürecinin gerektiği gözlemlenmiştir. Bunun nedeninin hekimlerin işleyişle ilgili bilgiye, tasarımcıların ise ürünleştirmeye yönelik bilgiye sahip olmasından kaynaklandığı düşünülmektedir.

Bu çalışmada "Ilham alma" sürecinde tasarımcılar her iki projede de, sorun tespitine ve daha iyi bir deneyim sunabilmeye olanak sağlayacak verileri toplamaya ihtiyaç duymuşlardır. Proje 1'de, literatürde dental fotoğraflama sürecinin hasta ve hekim deneyimi açısından incelenmesine yönelik bir araştırmaya rastlanamadığından, veri toplanması için alan çalışması yapılması gerekmiştir. İlgili sürecin hem mekanik hem de dijital birçok ekipmanın bir arada kullanımını gerektirmesi ve sürece dahil olan kişi sayısından, postürel zorlanmalara kadar birçok farklı sorunu içermesi nedenleriyle Proje 1'de, gözlem ve mülakat gibi kalitatif araştırma yöntemleri tercih edilmiştir. ${ }^{21,22} \mathrm{Ve}$ rilerin değerlendirilmesi aşamasında ise sürecin doğru şekilde yorumlanabilmesi için hekimler ile tasarımcıların birlikte çalışmaları gerekmiştir. Proje 2'de ise örneklemin hassas ve incinebilir bir topluluk olması ve hâlihazırda bu alanla ilgili yeterli düzeyde literatüre ulaşılabilindiğinden dolayı alan çalışması yerine ilgili literatürlerden veri toplanmıştır. Her iki projenin de "ilham alma" aşamasında benzer hedefler olmasına karşın bağlam farklılıkları sonucu farklı yaklaşımların sergilenmesi gerekmiş olup süreçte her iki disiplinden araştırmacılar kendi bilgi ve kaynaklarını kullanarak katkı sağlamıştır. Bu aşama, aslında var olan problemlerin ortak bir yaklaşımla tanımlanması ve çözüm önerilerinin geliştirilebilmesi için bir farkındalık oluşturulmasına katkı sağlamaktadır. Ayrıca yapılan ön araştırma, tasarım sürecinin sonraki aşamalarında geliştirilen çözümlerin daha geçerli olmasını sağlamıştır. Bu aşamada bilgi akışı ağırlıklı olarak hekimlerden tasarımcılara gerçekleşmiş olup iş birliği süreci ile ilgili üç tema tespit edilmiştir: (1) tasarımcıları yönlendirilmenin gerekliliği; (2) tasarımcıların sorun alanına ilişkin farklı bir perspektif sunması ve (3) hasta-odaklılık ile ilgili sorunların tespitinde ortak yorumlamanın önemi. Bu üç tema, "ilham alma" ve "fikirleştirme" aşamaları arasındaki süreci kapsayan "anlamlandırma" adı altında toplanmıştır.

"Fikirleştirme" aşamasında; Proje 1'deki bağlam daha kapsamlı olduğundan tasarımcılar tarafından birçok farklı tasarım önerisi geliştirilmiş olup doğru önerinin seçilmesi için sistematik bir değerlendirme süreci gerekmiştir ve bu amaçla tasarım alanındaki Pugh matriks analizi yönteminden faydalanılmıştır. Pugh matriks ana- lizi uygulanması için gerekli olan kriterler ise prosedüre ve klinik ortama hâkim olan uzman hekimler tarafından belirlenmiştir. Proje 2'de ise farklı tipte dudak-damak yarığına sahip bebeklerin ark formu ve boyutlarının incelendiği çalışmalardan faydalanılarak ilk tasarım önerisi oluşturulmuş ve bu öneri süreç içerisinde aşamalı olarak geliştirilmiştir. Tasarımcılar ilk önerinin ortaya çıkmasında serbest bırakılmış olsa da önerinin aşamalı olarak geliştirilmesinde düzenli olarak uzman geri-bildirimine ihtiyaç duymuşlardır. Bu doğrultuda fikirleştirme aşamasında iş birliği verimliliğini artıracak ve süreci hayata geçirme aşamasına bağlayacak 3 tema tespit edilmiştir: (1) ilk fikir geliştirme sürecinde tasarımcıların özgür bırakılması; (2) tasarımın doğru ilerlemesi için uzman görüşünün sağlanması ve (3) detaylandırma için tasarım alanına özgü yöntemlerden faydalanılması. Bu 3 tema, tasarımı "somutlaştırma"ya yönelik süreci ortaya koymaktadır.

"Hayata Geçirme" aşaması, her iki projede de hem tasarımcıların hem de uzman hekimlerin yoğun olarak dâhil olduğu bir aşama olmuştur. Tasarımcılar bu aşamada ağırlıklı olarak bilgisayar destekli olarak ürün detaylandırma ile ilgilenmiş olup uzman hekimler ise ürün tasarlama sürecini yönlendirmiş ve inovasyon sürecine dâhil olmuştur. Her iki projede de ürün tasarlama süreçlerinde eklemeli üretim yönteminden faydalanılmıştır. Proje 1'de (Tablo 2'de de görülebileceği üzere) "fikirleştirme" ve hayata geçme" aşamaları arasında daha lineer bir akış gerçekleşmiş olmakla birlikte, Proje 2'de bu süreç aşamalı bir ürün tasarlama sürecini gerektirdiğinden iç içe geçmiştir. Bu projede ayrıca olası olgu çeşitliliğine ilişkin sanal temsili modeller oluşturulmuş ve bu sanal modellerden üç boyutlu çıktı ile elde edilerek tasarım fikirlerinin denenmesine olanak tanınmıştır. Bu sayede fikirler "hızlı üretim" yöntemi kullanılarak prototipleştirilmiş ve tasarımın aşamalı olarak iyileştirilmesi sağlanmıştır. Aşamalı üretim ve prototiplerden faydalanılması ise tasarım odaklı düşünme yaklaşımının özüyle örtüşmektedir. Bununla birlikte bu aşamanın çıktılarının başta koyulan hedeflerle arasında bir ilişki olduğu gözlemlenmiş ve bu doğrultuda 3 tema oluşturulmuştur: (1) final ürünü ortak değerlendirmenin önemi; (2) hızlı prototiplendirmenin süreci kolaylaştırması ve (3) paydaşlara yönelik ortak somut fayda. Bu nedenle belirtilen üç tema dâhilinde, her iki projede de ortaya çıkan sonuçların başta konulan hedeflerle uyumluluğunu gözetebilmek ve disiplinler arası çalışmanın verimliliğini artırabilmek için bir "doğrulama" süreci yürütülmüştür.

\section{Kısıtlamalar}

Bu çalışmanın sonuçları değerlendirilirken ilgili kısıtlamaları da göz önünde bulundurulmalıdır. Araştırmaya dahil olan her iki tasarım da kendi içerisinde yetersizlikler barındırmaktadır. Çünkü bu araştırma ürün geliştirme sürecinin ilk aşaması olan "tasarım sürecini" ortaya koy- 
makta, ürünün hayata geçmesi için gerekli olan testler, üretime yönelik detayları (malzeme ve seri üretim yöntemi seçimi gibi) kapsamamaktadır. ${ }^{32-34} \mathrm{Bu}$ nedenle medikal bir ürünü kullanıma hazır hale getirilebilmesi için tasarım sürecini takiben, ilgili tasarımın uygun malzemeler ile prototiplendirilmesi ve kullanıcılarıyla test edilmesi de bir gerekliliktir. Bu model yalnızca ürün fikrinin ortaya çıkmasına olanak sağlayan uzman hekimler ve tasarımcılar arasındaki iş birliğine yönelik "tasarım geliştirme sürecine" odaklanmıştır. Ayrıca, çalışmada sunulmuş olan model yalnızca iki durum üzerinden geliştirildiğinden sınırlı bir kapsam ortaya koymaktadır. Bu doğrultuda daha fazla çalışmanın yapılması modelin daha da geliştirilmesine imkân sağlayacaktır.

\section{SONUÇ}

Ortodontik tedavi sürecinde kullanılan ekipmanların gerek hasta gerekse de hekim deneyimine olan bütünsel etkisi ve bu ekipmanların tasarım süreçlerinin ise meslek pratiği ile doğrusal ilişkisi ürün tasarlama sürecinde tasarımcı - hekim iş birliğini kaçınılmaz kılmaktadır. Bu bağlamda, iş birliği süreci; (1) ilham alma aşamasında bilgi akışının uzman hekimlerin yönetiminde ve tasarımcılara doğru olmasını; (2) fikirleştirme aşamasında tasarımcıların kendi uzmanlık yaklaşımlarıyla ama uzman hekimlerin yönlendirmesiyle ilerlemesinin gerekliliğini; (3) hayata geçirme aşamasında ise başta kararlaştırılan tasarım hedefleri ile ortaya çıkan tasarımın değerlendirilebilmesi için eş oranda bir katılımı gerektirmektedir. Bu çalışma sonucunda tasarım odaklı düşünme yaklaşımının ortodontiye yönelik ürün tasarlama sürecinde kullanımasına ilişkin önerilen iş birliği modeli Şekil 7'de sunulmuştur.

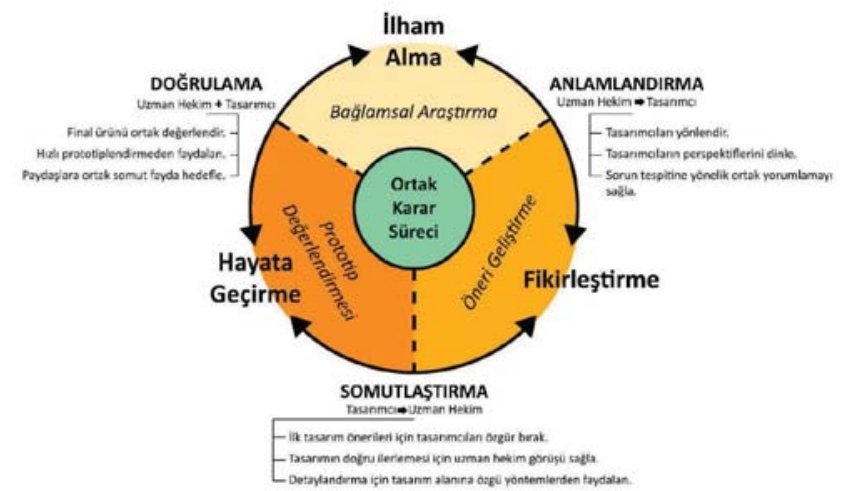

Şekil 7. Çalıșma sonucu önerilen, ortodonti alanına ait ürün tasarlama süreci iș birliği modeli

Bu örnek model yaklaşımı ile hasta odaklı çözümler geliştirilerek, ortaya çıkartılacak yeni tasarımların sağlık sisteminin kalitesini artıracağı düşünülmektedir.

Bu doğrultuda, tasarım sürecinin daha verimli ilerleyebilmesine olanak sağlayacak aşağıdaki öneriler dikkate alınabilir:

- Illham alma sürecinde tasarımcıların doğru hedeflere odaklanabilmesi için hekimlerin uzman bilgisinin ve konu ile ilgili araştırma verilerinin tasarımcıların kullanımına uygun bir şekilde aktarılması önemlidir. Bu noktada uzmanlık gerektiren tıbbi bilgilerin kritik bilgi kaybolmadan tasarımcıların anlayabileceği bir biçimde "anlamlandırılması", sürecin verimli ve hızlı bir şekilde ilerlemesini sağlayacaktır.

- Fikirleştirme aşamasında, farklı bir disiplinden olan tasarımcıların özgür bırakılması, daha farklı bakış açısına sahip fikirlerin ortaya çıkmasında önem teşkil etmektedir. Ancak fikirlerin alan uygunluğunun değerlendirmesi, uzman hekimlerle birlikte gerçekleştirilmelidir. Bu da tasarım konseptlerinin doğru şekilde somutlaştırılmasına olanak sağlayacaktır.

- Hayata geçirme aşamasında ise başta konulan hedeflerin "doğrulanması" önemlidir. Bu noktada, uzman hekimlerin ve tasarımcıların tasarlanan ürün üzerinde uzmanlık alanları doğrultusundaki farklı katkıları eş zamanlı olarak değerlendirilmelidir.

\section{TEŞEKKÜR}

Bu çalışmanın oluşturulması sürecinde fikir ve yardımlarından ötürü Mimar Sinan Güzel Sanatlar Üniversitesi Mimarlık Fakültesi Endüstri Ürünleri Tasarımı Bölümü öğretim üyeleri Doç. Dr. Abdüsselam Selami Çifter ve Dr. Öğr. Üyesi Yener Altıparmakoğulları'na teşekkürü borç bilirim.

\section{KAYNAKLAR}

1. Mills I, Frost J, Cooper C, Moles DR, Kay E. Patientcentred care in general dental practice-a systematic review of the literature. BMC Oral Health 2014; 5: 14-64.

2. Noort R. The future of dental devices is digital. Dent Mater 2012; 28: 3-12.

3. Walmsley AD. Transfertechnology in dentistry. Br Dent J 2003; 194: 226-7.

4. ADA Center for Evidence-Based Dentistry. Amerika Diş Hekimliği Birliği İnternet Sitesi 2019. Weblink: https:// ebd.ada.org/en/about

5. Güler D, Köprülü H, Güler AU Kanıta Dayalı Dişhekimliği (KDD). Ondokuz Mayıs Üniversitesi Dişhekimliği Fakültesi Dergisi. 2004; 5: 39-45

6. Green J, Britten N. Qualitative Research and Evidence Based Medicine. BMJ 1998; 316: 1230-1232.

7. Jack S. Utility of Qualitative Research Findings in Evidence-Based Public Health Practice. Public Health Nursing 2006; 23: 277-283.

8. Miller WR. Qualitative Research Findings as Evidence: Utility in Nursing Practice. Clin Nurse Spec 2010; 24: 191 193.

9. Britten N. Qualitative Research and the Take-Up of Evidence-Based Practice. Journal of Research in Nursing 2010; 15: 537-544.

10. Roberts JP, Fisher TR, Trowbridge MJ, Bent C. A design thinking framework for healthcare management and innovation. Healthc (Amst) 2016; 4: 11-4.

11. Buchanan R. Wicked problems in design thinking. 
Design Issues 1992; 8: 5-21

12. Brown T. Design thinking. Harvard Business Review 2008; June: 84-95

13. Hendricks S, Conrad N, Douglas TS, Mutsvangwa T. A modified stakeholder participation assessment framework for design thinking in health innovation. Healthc (Amst). 2018; 6: 191-196.

14. Yıldırım A, Şimşek H. Sosyal Bilimlerde Nitel Araştırma Yöntemleri. Ankara, Seçkin Yayıncılık, 2016.

15. Yin R. Case Study Research and Applications: Design and Methods. 6th Ed., Los Angeles, SAGE Publications, 2018.

16. Sandler J, Murray A. Digital Photography in Orthodontics. Journal of Orthodontics 2001; 28: 197-201.

17. Ogodescu A. S, Sinescu C, Ogodescu E. A, Negrutiu $M$, and Bratu $E$, Digital Tools in the Interdisciplinary Orthodontic Treatment of Adult Patients. International Journal of Biology and Biomedical Engineering 2010; 4: 97-105.

18. Fahim R. and Thakur R. Digital Dental Photography: The Guidelines for a Practical Approach. TMU Journal of Dentistry 2014: 1: 106-112.

19. Morse G. A., Haque M. S., Sharland M. R., and Burke F. J. T. The Use of Clinical Photography by UK General Dental Practitioners. British Dental Journal 2010; 208(E1): 1-6. 20. Yilmaz H., Bilgic F., and Sozer O. A. Recent Photography Trends in Orthodontics. Turkish Journal of Orthodontics 2016; 28: 113-121.

21. Çifter M. A Qualitative Analysis of Dental Photography in Orthodontics: The Patient's Perspective. BiomedResInt. 2018; E-5418592.

22. Altıparmakoğulları $Y$, Çifter $M$, Çifter AS. A multidisciplinary inspection of dental photography: What do dentist think and what can designer do?. The Design Journal 2017; 20: 1989-1997

23. Patton, MQ. Qualitative research and evaluation methods. Thousand Oaks, CA: Sage Publications, Inc. 2015.

24. Robson, C. Real world research: A resource for users of social research methods in applied settings. Chichester, West Sussex: Wiley. 2011

25. Pugh S Total Design: Integrated Methods for Successful Product Engineering, Reading, Addison-Wesley, 1991.

26. Cervone HF. Applied digital library project management: Using Pugh Matrix Analysis in complex decision-making situations. OCLC Systems \& Services: International Digital Library Perspectives 2009; 25: 228-232.

27. Berman B. 3-D printing: The new industrial revolution. Business Horizons 2012; 55: 155-162

28. Jacobson BN, Rosenstein SW. Early maxillary orthopedics for the newborn cleft lip and palate patient. An impression and appliance. Angle Orthod 1984; 54: 247-63.

29. Monga N, Kharbanda OP. A Pristine Approach for the Prominent Premaxilla in Bilateral CleftLip and Palate
(BCLP) Cases. Cleft Palate Craniofac J 2019; 56: 11151119.

30. Patel J, Winters J, Walters M. IntraoralDigital Impression Techniquefor a NeonateWithBilateral CleftLip and Palate. Cleft Palate Craniofac J 2019; 56: 1120-1123.

31. Çelikel ADG. Tek ve çift taraflı primer ve sekonder damak yarığı bulunan farklı yaş gruplarındaki bireylerin ark formu ve boyutlarının değerlendirilmesi. Doktora Tezi - İstanbul Üniversitesi, Diş Hekimliği Fakültesi, Ortodonti Anabilim Dalı, 2010.

32. FDA. Design Control Guidance for Medical Device Manufacturers. U.S.: Center for Devices and Radiological Health, Food and Drug Administration. 1997.

33. Alexander K., Clarkson J. A validation model for medical devices industry. Journal of Engineering Design 2002; 13: 197-204.

34. Shah S. G. S, Robinson I., AlShawi S.. Developing medical device technologies from users' perspectives: A theoretical framework for involving users in the development process. International Journal of Technology Assessment in Health Care. 2009; 5: 514-521. 